\title{
UM CONTO DE DUAS CRISES: PESQUISA E REDAÇÃO DE O CAPITAL ENTRE 1857 E 1868
}

A tale of two crises: research and writing process of Marx's Capital between 1857 and 1868

Leonardo Gomes de Deus *

Resumo: $\mathrm{O}$ artigo examina a influência das pesquisas conjunturais de Karl Marx a respeito das crises de 1857 e 1866 sobre o processo de redação de O Capital e, por outro lado, o impacto dessa redação na própria análise marxiana das crises econômicas.

Palavras-chave: Karl Marx. Crise econômica. O Capital. Teoria econômica.

Abstract: The paper addresses the influence of Karl Marx's empirical researches related to the crises of 1857 and 1866 on the process of writing Capital and the impact of this process on Marx's own analysis of economic crises.

Key-words: Karl Marx. Economic crises. Marx's Capital. Economic theory.

* Professor do Cedeplar/FACE/UFMG. Artigo recebido em 13/09/2019 e aprovado para publicação em 18/11/2019. 


\section{Introdução}

" obra de Marx", "a teoria de Marx", enfim, o pensamento marxiano não existe acabado desde sempre; foi uma construção de mais de 1 século. Hobsbawm (1979), há muito tempo, apontou exatamente esse ponto fundamental: em todos os momentos de ruptura do comunismo no século passado, a obra de Marx foi redescoberta, viu seu escopo crescer e também a crítica a seus princípios. 1917, 1956, 1968, 1989 marcam precisamente alguns dos pontos de inflexão no destino da obra marxiana e em sua recepção. No momento em que se celebram o bicentenário de Marx, o sesquicentenário de $O$ Capital e os cinquenta anos de maio de 1968, a obra marxiana permanece objeto de renovado interesse. Este artigo pretende investigar alguns elementos importantes a respeito dos estudos de Marx sobre duas crises econômicas que testemunhou e estudou com atenção, aquelas de 1857 e de 1866. Entre uma e outra crise, Marx também redigiu boa parte de sua obra econômica, portanto, busca-se aqui avaliar como os estudos conjunturais foram transformados pela redação da teoria econômica e, por outro lado, como essa redação influenciou o próprio estudo conjuntural. Além desta introdução e de uma conclusão, este artigo se divide em quatro seções, a primeira trata do contexto marxiano em 1868, a segunda e a terceira analisam, respectivamente, as leituras de Marx sobre as duas crises e a quarta propõe uma síntese entre uma e outra tarefa intelectual levada a termo por ele no período. ${ }^{1}$

\section{Marx em 1868 , entre a pesquisa e a redação}

No início de 1868, Marx estava bastante otimista. O movimento revolucionário retomava sua fase de expansão, o primeiro volume do Capital acabava de ser publicado. É a conclusão de uma década - de 1857 a 1867 - que apresenta uma série de rupturas, instaurações e consolidações. Basta dizer que Marx redigiu dois esboços para o livro de 1867, os Grundrisse e o Manuscrito de 1861-1863, que também abordam vários outros temas. Entre 1864 e 1865, escreveu o principal manuscrito para o livro terceiro. Em meio à redação desse texto, esboçou o livro segundo pela primeira vez, o "Manuscrito I" (MEGA², II.4.1, pp. 138-381), em meio a todas as atividades da nascente Internacional. Diante disso, nos idos de abril de

\footnotetext{
${ }^{1}$ As ideias aqui desenvolvidas foram apresentadas em 2018, no seminário da FAJE, por ocasião do bicentenário. Agradeço a oportunidade, os comentários feitos por uma distinta plateia e, em especial, as sugestões formuladas por meus estimados colegas Édil Guedes, Ramon Maia e Guilherme Oliveira. Também agradeço as inestimáveis contribuições dos colegas do Grupo de Economia Política Contemporânea da UFMG. Isento-os, evidentemente, de qualquer responsabilidade.
} 
1868, em meio a doenças e dívidas, ele troca algumas cartas com Engels sobre os planos de conclusão de $O$ Capital. Na carta de 22 de abril, por exemplo, há uma breve discussão sobre queda da taxa de lucro e o valor do dinheiro. ${ }^{2}$ Diante da resposta de Engels, em 30 de abril, Marx se detém em algumas questões a respeito de seu trabalho naqueles dias:

“No entanto, é certo que você conheça o método de desenvolvimento da taxa de lucro. Assim, apresento-lhe a trajetória em linhas as mais gerais. Como sabe, no Livro II, o processo de circulação do capital será apresentado sob os pressupostos desenvolvidos no livro I. Portanto, as novas determinações formais que se originam do processo de circulação, como capital fixo e circulante, rotação do capital etc. Finalmente, no livro I, contentamo-nos em assumir que, se, no processo de valorização, $£ 100$ se tornam $£ 110$, eles encontram no mercado os elementos nos quais eles novamente se convertem. Entretanto, agora, investigamos as condições sob as quais esses elementos são encontrados, portanto, o entrelaçamento social dos diversos capitais, partes do capital e da renda $(=\mathrm{m})$ uns com os outros.

Assim, no livro III, chegamos então à transformação do mais-valor em suas diversas formas e partes componentes separadas.

I. Lucro é para nós, em primeiro lugar, apenas outro nome ou outra categoria para mais-valor. Assim como a forma do salário aparece como o pagamento a todo o trabalho, a sua parte não paga aparece necessariamente não como proveniente do trabalho, mas do capital, não da sua parte variável, mas como do capital total. Com isso, o mais-valor assume a forma do lucro, sem diferença quantitativa entre um e outro. Um é apenas a forma de manifestação ilusória do outro."

Depois de explicar a categoria preço de custo, ou seja, o fato de que o capitalista possa vender sua mercadoria abaixo do valor, mas nunca abaixo do preço de custo, Marx ainda explica a Engels a diferença fundamental e contrastante entre taxa de mais-valor e taxa de lucro. Segundo ele, distinção marcante, ao contrário daquela entre lucro e mais-valor. Por conta disso, explicita algo que, durante os próximos 150 anos permaneceria obscuro, em certa medida:

"Diante daquilo que se desenvolve no livro II, no entanto, segue que a taxa de lucro não pode ser computada a partir de um produto-mercadoria arbitrário, por exemplo, de uma semana, mas que $\frac{m}{c+v}$ significa aqui o mais-valor produzido durante um ano em relação ao capital adiantado durante o ano (distinto do capital que faz a rotação de um ano). $\frac{m}{c+v}$ é aqui, portanto, a taxa de lucro anual.

Então, investigamos, em primeiro lugar, como diferentes rotações do capital (parcialmente dependentes da proporção da parte circulante em relação à fixa

${ }^{2}$ MARX, Karl. Briefe über Das Kapital. Berlim: Dietz, 2010, p. 127.

${ }^{3}$ Ibidem, p. 130. 
do capital, parcialmente do número de rotações do capital circulante num ano etc. etc.) modificam a taxa de lucro diante da taxa de mais-valor constante. Entretanto, pressuposta a rotação e dada $\frac{m}{c+v}$ como taxa de lucro anual, investigamos como ela pode-se modificar, independente de modificações na taxa de mais-valor e mesmo em sua massa.

Como m, a massa de mais-valor, = à taxa de mais-valor multiplicada pelo capital variável, então, se chamamos a taxa de mais-valor t e a taxa de lucro $\mathrm{l}^{\prime}, \mathrm{l}^{\prime}=\frac{t \cdot v}{c+v}$. Temos aqui quatro variáveis, $\mathrm{l}^{\prime}, \mathrm{t}, \mathrm{v}$ e $\mathrm{c}$, com 3 das quais podemos trabalhar, sempre investigando a quarta como desconhecida. Isso resulta em todos os casos sobre os movimentos da taxa de lucro, na medida em que são distintas do movimento da taxa e, to a certain extent, mesmo da massa de mais valor. Isso, naturalmente, foi inexplicável por todos até agora.

As leis assim descobertas, muito importantes, por exemplo, para se entender a influência do preço da matéria-prima na taxa de lucro, essas leis permanecem corretas qualquer que seja a divisão posterior do mais-valor entre produtor etc. Isso só pode modificar a forma de aparência. Além disso, elas permanecem diretamente aplicáveis, se $\frac{m}{c+v}$ é tratada como relação do mais-valor produzido socialmente com o capital social." ${ }^{4}$

Muitos dos descaminhos exegéticos do século passado, em especial o falacioso "problema da transformação", seriam evitados se essas pistas tivessem sido interpretadas com alguns dos manuscritos produzidos naqueles anos. Infelizmente, os Manuscritos de 1867-1868 só foram publicados em 2012 e demonstram duas coisas: as dificuldades formais de promover a síntese entre as categorias dos livros I e II, que deveria ser efetuada no livro III; a consistência dos planos de Marx para a redação de sua obra econômica no período aqui tratado. ${ }^{5}$ Cabe dizer apenas que, na mencionada carta, Marx prossegue por mais algumas páginas a enunciar todo o plano, passando por taxa de lucro-médio, lei tendencial da queda de lucro, capital mercantil, capital portador de juros, transformação do lucro suplementar em renda da terra e o arremate da obra:

“Finalmente, como essas três formas de manifestação (salário, renda da terra, lucro (juros)) aparecem como as fontes de renda das 3 classes, proprietários, capitalistas e trabalhadores - a luta de classes como conclusão, em que o movimento e a dissolução de toda essa merda se resolvem." ${ }^{6}$

As linhas gerais estavam dadas há alguns anos e a publicação do livro primeiro apontava uma trajetória exequível do ponto de vista formal. Os problemas que Marx enfrentará para concluir os dois livros decorrem do próprio momento por que passava a sociedade capitalista. Com efeito, a

\footnotetext{
${ }^{4}$ Ibidem, p. 132.

${ }^{5}$ Devo a Fred Moseley a advertência a respeito de todos esses problemas e a instigante agenda de pesquisa que nos proporcionam.

${ }^{6}$ Ibidem, p. 135.
} 
década de 1860 apresentou notáveis acontecimentos na vida econômica dos povos, em especial, as inovações financeiras, a internacionalização acelerada do capital, notadamente a partir da Guerra Civil Americana, além de várias inovações tecnológicas, tudo a chamar a atenção de Marx. Em outras palavras, a pesquisa, ao contrário do que nosso autor acreditava no início da década, não estava concluída, aberto que estava o próprio objeto em mutação. Vollgraf assim se expressou a respeito:

“Como Marx realizaria uma exposição empírica similar [ao livro I - LGD] nos livros II e III? No livro II, ele poderia vividamente apresentar as batalhas intensas de interesses opostos de compradores e vendedores no mercado, ou ilustrar a rotação do capital com referência às ferrovias (em que investimentos imensos de capital estavam envolvidos e que só podiam ser recuperados lentamente). Marx poderia ter considerado as vantagens das três formas de depreciação, sobre as quais questionou Engels por anos, e poderia ter descrito vividamente a luta das companhias de estradas de ferro a respeito de tarifas de transporte e de participação no mercado. Tais discussões se encontram em dois esboços para o livro II apenas em linhas gerais, embora sejam cobertas nas leituras de Marx e em seus cadernos de notas." ${ }^{7}$

A própria pesquisa estava longe de ser concluída. $\mathrm{O}$ balanceamento correto entre empiria e teoria, alcançado no primeiro livro, ainda não havia sido obtido para as partes seguintes, de fato, nunca o seria. Além disso, Vollgraf ainda aponta outro problema crucial daqueles anos: o método de exposição pretendido por Marx sofreria vários reparos em razão de suas incursões no terreno da matemática. ${ }^{8} \mathrm{O}$ nível de abstração que pretendia conferir à sua obra implicava o desenvolvimento de um método de exposição compatível com as "leis gerais do movimento", exatamente como descritas na carta de 1868 e como esboçado nos manuscritos desse ano. Precisamente a partir dos problemas decorrentes da atuação recíproca de diversas variáveis nas tendências do movimento, seria necessário um aparato quantitativo que não estava disponível para nenhum economista do final do século XIX. Isso aparece nitidamente nos referidos Manuscritos de 1867-1868, ${ }^{9}$ bem como nos manuscritos matemáticos da última década de Marx. ${ }^{10}$

Seja como for, vencida a publicação da primeira edição do livro I, uma tarefa era prioritária para Marx em 1868. Ao mesmo tempo em que escrevia os diversos manuscritos para os livros II e III, ele se lança ao estudo da crise de 1866, que não pudera estudar devidamente em razão de sua atuação na

\footnotetext{
${ }^{7}$ VOLLGRAF, Carl-Erich. Marx's further work on Capital after publishing volume I: on the completion of part II of the MEGA². LINDEN, Marcel van der. HUBMANN, Gerald. Marx's Capital: an unfinishable project? Leiden: Brill, 2018, p. 72.

${ }^{8}$ Cf. Ibidem, p. 74.

${ }^{9}$ MARX, Karl. ENGELS, Friedrich. Gesamtausgabe, II.4.3. Berlim: Akademie, 2012.

${ }^{10}$ MARX, Karl. ENGELS, Friedrich. Gesamtausgabe, II.14. Berlim: Akademie, 2003.
} 
Internacional e, sobretudo, graças a sua imersão na redação final do livro de 1867. Tomado de grande surpresa, em 1868, ele recebe convite de Nikolai Danielson para a tradução russa de seu livro. Danielson lhe propusera o envio até mesmo dos manuscritos em elaboração, para que houvesse o lançamento simultâneo dos livros restantes no idioma original e no russo. Marx assim respondeu em 7 de outubro de 1868: "Você não deve esperar pelo segundo volume, cuja publicação talvez seja adiada ainda por 6 meses. Eu não posso terminá-lo até que certas enquetes oficiais, iniciadas no ano passado (e em 1866), sejam concluídas ou publicadas. A propósito, o volume I constitui um todo acabado." ${ }^{11}$ A primeira tarefa, portanto, era a investigação de mais uma crise econômica, ou seja, Marx continuava a tratar as crises como uma oportunidade revolucionária, mas, também, como um momento especial do funcionamento da economia capitalista. Esse material tem sido estudado, embora nunca tenha sido publicado. Por outro lado, somente em 2017 as anotações de Marx sobre a crise de 1857 vieram a público. ${ }^{12}$ Como se disse acima, entre uma e outra crise, o plano geral e boa parte dos manuscritos para os livros I e III foi redigida. Duas coisas devem ser investigadas aqui: se a perspectiva marxiana sobre as crises sofreu modificações entre 1857 e 1868; se essa perspectiva pode ser lida à luz do livro III.

\section{A hipótese da "crise dupla" (1857)}

Os estudos conjunturais de Marx sofreram grande evolução a partir de sua mudança para Londres. Passou a contar com dados empíricos das mais variadas naturezas. Suas anotações do semanário The Economist, gradualmente, aprimoraram sua perspectiva sobre crise e ciclo. Ao mesmo tempo, jamais deixou de estudar toda a bibliografia teórica disponível no período. Quando eclode a crise de 1857, portanto, está mais bem preparado para estudá-la do que em sua fase continental. Desde sempre, repita-se, sob a perspectiva de que uma crise econômica aceleraria o movimento revolucionário e promoveria a derrubada do capitalismo. Essa visão apareceria, de modo translúcido, nos Grundrisse, redigidos no mesmo período, isto é, a contradição entre formas de intercâmbio e forças produtivas levaria o capitalismo a seu fim. A crise de 1857 parecia ser um sinal definitivo dessa trajetória.

Essa crise, de fato, foi considerada a crise mais severa enfrentada pela Inglaterra ou qualquer outro país até então. Essa é a opinião, v.g., de David Morier Evans, em seu livro de 1859 sobre a crise. ${ }^{13}$ Para esse autor,

\footnotetext{
${ }^{11}$ MARX, Karl. ENGELS, Friedrich. Werke, v. 32. Berlim: Dietz, 1974, p. 563.

${ }^{12}$ MARX, Karl. ENGELS, Friedrich. Gesamtausgabe, IV.14. Berlim: De Gruyter Akademie, 2017. A partir daqui, citado como MEGA2 IV.14.

${ }^{13}$ EVANS, David Morier. The history of the Commercial Crisis, 1857-1858, and the stock exchange panic of 1859. Londres: Groombridge \& Sons, 1859, p. 46.
} 
a diferença da crise de 1857-58 em relação a outros pânicos da primeira metade do século se deveu a seu alcance e a sua expansão acelerada. A nova crise teria sido mais profunda porque teria eclodido no coração de uma especulação mais aguda, qual seja, a especulação com papéis de ferrovias, elemento novo daquele momento. As causas da crise, conquanto complexas, estão ligadas a elementos da expansão econômica em direção ao oeste americano: imigração, com expectativa de expansão das ferrovias, especulação com terras e, finalmente, a própria especulação com títulos. A causa imediata foi a quebra de diversas instituições que tomavam dinheiro emprestado para especular com títulos de ferrovias e hipotecas. Os preços das ações das ferrovias e o preço da terra no meio-oeste americano caíram drasticamente a partir do segundo semestre de 1857, levando à quebra sucessiva de vários bancos, até atingir a própria Inglaterra. ${ }^{14}$ De acordo com Evans, três fatores tornaram a crise mais grave ainda: expansão sem precedentes do comércio exterior, expansão da oferta de metais preciosos e desenvolvimento "monstruoso" do sistema bancário. ${ }^{15}$ Assim como foi dramática e aguda, a recuperação também teve início de modo rápido e inesperado, já em janeiro de 1858 .

Com 192 páginas, as anotações de Marx compreendem três cadernos, redigidos entre novembro de 1857 e fevereiro de 1858, tendo a maior parte das referências provindo da Economist. O primeiro caderno, "1857 - França", possui quarenta páginas e aborda esse país, possivelmente, em razão das atividades jornalísticas de Marx. O caderno cobre as tentativas do governo imperial e do Banco da França de salvar companhias ferroviárias com vários vínculos junto às ferrovias americanas. A principal solução encontrada pelo governo francês para resolver o problema de liquidez, diante da elevada taxa de juros (para conter a drenagem de ouro em direção ao exterior), foi garantir a circulação de papéis bancários no lugar do próprio ouro. ${ }^{16}$ A partir de novembro, a crise chegou a vários negócios na França, mas, ao contrário do que se esperava, a crise não implicou falências generalizadas, tão somente a contração do comércio e da indústria. O grande problema consistiu no adiamento de diversos pagamentos, mas isso não causou o esperado pânico no mercado financeiro francês. O Banco da França operou, na crise, como um banco central moderno, garantindo liquidez e preservando o balanço de pagamentos, mesmo que à custa da elevação do endividamento das empresas e do próprio governo. Assim, ao contrário de Londres, Hamburgo, Viena, Berlim etc., na França apenas os comerciantes medíocres ("petty") acabaram por enfrentar falência. ${ }^{17}$ Todos esses fatos estão explícitos no balanço de novembro do Banco da

\footnotetext{
${ }^{14}$ Cf. CALOMIRIS, Charles W.; SCHWEIKART, Larry. The panic of 1857: origins, transmission, and containment. The Journal of Economic History, 51 (4), 1991, p. 811.

${ }^{15}$ Ibidem, p. 32.

${ }^{16}$ MEGA $^{2}$ IV.14, p. 14.

${ }^{17}$ MEGA $^{2}$ IV.14, p. 14, 27.
} 
França, com diminuição de títulos lastreados em ouro, aumento de notas bancárias, adiantamentos de cobrança de empréstimos, fundos e liquidação diferida de títulos de ferroviais. O papel-moeda teve sua circulação superlativamente aumentada, enquanto os descontos de notas caíram sobremaneira. ${ }^{18}$ A parte final do primeiro caderno se encerra com notas sobre importações (cadentes em 1857), receita do governo (crescentes ao longo do ano, embora a contabilidade pública também levasse em conta impostos "a receber") e, finalmente, a retomada da atividade das ferrovias. A partir de janeiro de 1858, o endividamento das empresas voltou ao normal e o Banco da França pôde retomar o corte de juros, depois da pior elevação por que já havia passado.

Com 74 páginas, o segundo caderno foi iniciado em 12 de dezembro de 1857 e recebeu o título de "Book of the Crisis of 1857", cobre prioritariamente a economia inglesa. Ao contrário da França, o número de falências na Inglaterra foi assustador e as medidas tomadas vieram mais tarde. As medidas francesas, ao final, implicaram uma drenagem de ouro do Banco da Inglaterra para a França. Estava-se na vigência do Bank Charter Act de 1844, que implicava a busca, pelo Banco da Inglaterra, de uma proporção fixa de ouro em seu balanço, ou seja, havia uma restrição monetária intrínseca às práticas do Banco, o que causava, em momentos de crise, não apenas a elevação dos juros, mas a retirada de papel-moeda de circulação. Tratava-se, portanto de política monetária pró-cíclica, o que tornava pânicos e crises mais graves ainda. Tanto em 1857 quanto nove anos depois, a lei teve sua aplicação suspensa para que se socorressem os agentes do mercado. Diante disso, o segundo caderno enumera as diversas falências havidas na Inglaterra, além de se ocupar do balanço do Banco da Inglaterra.

A lei de 1844 representou uma contração monetária muito forte e, ao mesmo tempo, com as medidas do outro lado do Canal da Mancha, uma drenagem acelerada de ouro, a tal ponto que a lei foi suspensa em novembro. Marx cita a Economist de 14 de novembro;

"A crise monetária atingiu seu clímax nesta semana. Durante todo o início da semana, o sentimento de desconfiança continuou a crescer. A demanda por dinheiro junto ao Banco da Inglaterra foi sem precedentes; ainda assim, a despeito de todas as imensas somas de dinheiro obtidas desse estabelecimento, a dificuldade de se obter acomodação no mercado aberto se tornou mais decisiva do que nunca. Na quinta-feira pela manhã, havia o perigo de os negócios comerciais chegarem a um ponto de paralisação. Por volta de 3 e meia, por parte do Banco da Inglaterra, foi oficialmente notificada a suspensão do Bank act de 1844. As grandes casas de desconto e outras firmas tiveram permissão de obter grande oferta de dinheiro do Banco da Inglaterra, e começaram imediatamente uma grande acomodação liberal. Na sexta, embora ainda altas, estavam bem abaixo daquelas do dia anterior."19

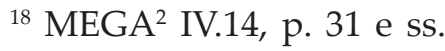

${ }^{19}$ MEGA $^{2}$ IV.14, p. 84. 
Diante desse quadro, nos dias que se seguiram, houve uma grande expansão de notas privadas, do Banco da Inglaterra e de outros bancos, uma diminuição da reserva de ouro. Em cinco semanas, houve cerca de 5\% de aumento no papel-moeda em circulação, decréscimo de mais de $40 \%$ nas reservas de ouro, cerca de $50 \%$ de aumento nos depósitos e expansão de quase $50 \%$ dos títulos privados. A taxa de juros passou de $6 \%$ em 10 de outubro para $10 \%$ de novembro. A pressão monetária continuaria nas semanas seguintes, embora, gradualmente, o balanço do Banco da Inglaterra começasse a melhorar, sempre do mesmo modo. Em janeiro de 1858, a crise parecia ser superável. Uma das explicações para o pânico e o nível da queda dos meses anteriores já se fazia notar. Marx cita a Economist de 23 de janeiro a respeito:

"A explicação da recente crise monta a isso, especialmente - que, neste país, e na maior parte das comunidades comerciais às quais está ligado, nos últimos 5 ou 6 anos, crescera gradualmente um grande círculo de firmas que levaram a termo um enorme comércio de exportáveis e importáveis, não por meio de capital próprio, mas por meio de capital levantado pela sistemática emissão e desconto de notas de câmbio de liquidação; que, depois de várias escapadas estreitas do colapso, desde o verão de 1855, a quebra veio finalmente na forma mais devastadora, com a quebra simultânea (e de onde veio essa simultaneidade?) de vários grandes centros dos quais a coerência do sistema dependia; e isso, de fato, quando desapareceram todos os mistérios de emissão e nova emissão, desconto e redesconto, ficou perfeitamente claro que as massas do capital real realmente manejadas por aqueles aventureiros foram obtidas por eles na forma de descontos e adiantamentos, e as altas reservas de juros, foram obtidas de reservatórios de depósitos mantidos por firmas como o Western Bank of Scotland, e a partir de reservatórios de capital sob o comando de industriais, corretores e distribuidores, de quem os aventureiros obtinham crédito e para quem, claro, restava apenas tanta satisfação quanto a coberta por um dividendo infinitesimal. Será um grande infortúnio se qualquer parte do público for levada à crença de que seja possível conceber e conduzir qualquer sistema de mero crédito de papel, o que será igual, por anos, a criar e conduzir um imenso comércio, especialmente exterior. Crédito não pode fazer algo do nada. Para uma grande parte do comércio, é preciso haver uma oferta de moeda de algum lugar." ${ }^{20}$

Um diagnóstico muito frequente naqueles dias era, assim, a visão moral das crises. A Inglaterra passava por mudanças em seu sistema bancário e a visão que se tinha de usura e especulação remontava à crise de 1720. Essa visão moral da crise permaneceu viva e ressurgiria, a partir dali, a cada pânico até este século. Mesmo com a construção de sua obra econômica ainda no nascedouro, essa perspectiva, naturalmente era absolutamente estranha à perspectiva marxiana. A natureza do processo, acreditava Marx já em 1857, era mais complexa do que as intenções morais dos agentes. Com efeito, o plano esboçado no segundo caderno de 1857 parece ter uma

${ }^{20}$ MEGA $^{2}$ IV.14, p. 105, grifos de Marx, bem como os parênteses. 
intenção nítida, a pretensão de captar todos os fenômenos econômicos, tornados nítidos no momento de ruptura da crise. Assim, Marx parte dos fenômenos mais aparentes, o mercado monetário, ${ }^{21}$ que compreende "visão geral", "mercado de câmbio", "mercado de títulos" para, finalmente, analisar o "mercado de produtos" (matérias-primas) e o "mercado industrial". As quedas drásticas de importações e exportações verificadas em 1857, para Marx, não poderiam ser mero fruto de especulação e ações imorais dos agentes. Elas eram, ademais, o ponto de ligação entre as diversas praças do mundo capitalista de então, razão pela qual, nas páginas seguintes do manuscrito, Marx investiga os efeitos da crise em Hamburgo e Viena, afetadas após o pânico inglês, com flutuações similares em taxas de juros e em expansões monetárias. ${ }^{22}$ Nessa rede mundial, o comércio entre Estados Unidos e Inglaterra mereceu de Marx atenção detalhada. Entre novembro de 1856 e novembro de 1857, as exportações inglesas diminuíram 72\%. Os analistas de então continuavam a responsabilizar questões morais e, sobretudo, a denunciar uma espécie de competição entre várias partes do globo. ${ }^{23}$ De todo modo, com a crise, ficou claro para os ingleses que seu déficit comercial não poderia ser sustentado, visão bastante limitada diante da grandiosa exportação de capitais por parte da própria Inglaterra.

A segunda parte do segundo caderno prossegue com uma nova rodada de notas com o mesmo plano. A partir de dezembro, a recuperação parecia factível ao próprio mercado. ${ }^{24} \mathrm{~A}$ derrubada do capitalismo não ocorrera conforme previsto, não conseguiu nem ao menos tornar a atuação do proletariado mais vívida no período, já que o trabalho esporádico se tornara mais escasso e as perspectivas pareciam desastrosas. Por outro lado, no final de 1857, a confiança era completa, a ponto de o Banco da Inglaterra reduzir a taxa de juros. ${ }^{25}$ Por outro lado, o mercado de produtos (matérias-primas) parecia recuperar-se aceleradamente, com aumentos de preços em todo o mundo. A análise marxiana, nesse quesito, é detalhada, a acompanhar a evolução de diversos produtos, algodão, seda, lã, cânhamo, linho, metais, carvão, peles, couro, açúcar, café, cacau, índigo, drogas, milho, corantes. Marx cita quase textualmente a seguinte nota da Economist de 26 de dezembro de 1857: "Notável suavidade da estação: 2 ou 3 noites de geada, em cada ocasião, extremamente reduzida. (...) Preços de todos os tipos de grão caíram; assim como preço da lã; cabeças de gado e ovelhas também estão consideravelmente mais baratos do que nos últimos tempos. A maior queda ocorreu com suínos, que, em alguns distritos, não valem metade do que valiam junho passado." 26

\footnotetext{
${ }^{21}$ MEGA $^{2}$ IV.14, p. 90 e ss.

${ }^{22}$ MEGA $^{2}$ IV.14, p. 111 e ss.

${ }^{23}$ MEGA $^{2}$ IV.14, p. 155.

${ }^{24}$ MEGA $^{2}$ IV.14, p. 207.

${ }^{25}$ MEGA $^{2}$ IV.14, p. 208.

${ }^{26}$ MEGA $^{2}$ IV.14, p. 250.
} 
Finalmente, o segundo caderno percorre, em sua conclusão, o "mercado industrial". O declínio constante de preços provocou dispensas, falências, cancelamento de encomendas de matérias-primas. Em 12 de dezembro de 1857, Marx cita o The Times, sobre a indústria têxtil de Manchester: "Poucas vendas foram feitas nesta manhã, e todos os negócios realizados nesta semana caíram abaixou das vendas de qualquer outra semana anterior, durante a presente crise. Fabricantes dizem que não se recordam de uma estagnação mais completa do comércio, pois, embora a média da produção do distrito não exceda metade da quantidade produzida, os estoques estão a acumular rapidamente." ${ }^{27}$ Nas páginas seguintes do caderno, Marx tomará várias notas similares, ou seja, o mercado industrial foi o último a cair e o que caiu mais drasticamente, quando já se anunciava a recuperação do mercado de capitais. Em 14 de dezembro, novamente o The Times descreve a situação em Manchester: "Enquanto a pressão monetária está a diminuir em Londres, ela está a aumentar neste distrito. (...) Eles [empresários - LGD] estão a acumular estoques, embora sua produção esteja enormemente reduzida; e, por isso, assim como em razão da perda com a queda dos preços, eles, por sua vez, sentem mais do que nunca a necessidade de dinheiro.", ${ }^{28}$ Notícias similares são anotadas na página 263 , recuperação no mercado de capitais e estagnação na indústria e no comércio .

Os efeitos sobre o emprego, naturalmente, fizeram-se sentir. Reuniões de trabalhadores desempregados ocorreram, com provas de rápido empobrecimento e desocupação. O Sheffield Independent de 26 de dezembro mostrou que os salários teriam caído, em comparação com 1856, para cerca de um terço. Algumas firmas chegaram a pagar metade do salário, enquanto outras, apenas um quarto. ${ }^{29}$ Somente no final do ano, por outro lado, a confiança pareceu retornar e a impressão generalizada, na virada do ano, era de que o pior havia passado. ${ }^{30} \mathrm{O}$ segundo caderno, no entanto, encerra-se exatamente com notícias sobre o desemprego ainda persistente.

Com 81 páginas, o terceiro caderno recebeu o título "The Book of the Commercial Crisis". Interessante notar como Marx ainda utilizava com frequência esse termo, "crise comercial", para designar qualquer crise econômica. O manuscrito foi iniciado em janeiro de 1858 e segue o mesmo plano do segundo, ou seja, parte do mercado de capitais, para chegar aos diversos mercados de produtos. As últimas anotações incluem o mercado de café brasileiro, com expansão entre 1854 e 1856 e uma queda de mais de $10 \%$ durante a crise ${ }^{31}$ Esse caderno, ao contrário dos dois anteriores,

${ }^{27}$ MEGA $^{2}$ IV.14, p. 254.

${ }^{28}$ MEGA $^{2}$ IV.14, p. 256.

${ }^{29}$ MEGA $^{2}$ IV.14, p. 258.

${ }^{30}$ MEGA $^{2}$ IV.14, p. 273.

${ }^{31}$ MEGA $^{2}$ IV.14, p. 500. 
descreve exatamente a recuperação dos diversos mercados, especialmente o monetário. Em janeiro de 1858, os títulos privados em poder do Banco da Inglaterra começam a diminuir, assim como a taxa de juros. ${ }^{32} \mathrm{O}$ setor real da economia, matérias-primas e a própria indústria, era o de mais lenta recuperação, com preços muito baixos em janeiro de 1858 e as dívidas do setor ainda muito altas. Com isso, as notas em posse de bancos, responsáveis por seu aperto alguns meses antes, continuavam a pesar sobre seus passivos no início do ano. A visão que se tinha, ainda, era de que provinham de especulação, dos "aventureiros". ${ }^{33}$ Seja como for, o mercado de crédito começava a dar sinais de recuperação no período. A primeira semana de janeiro, com efeito, com a publicação de um balanço por parte do Banco da Inglaterra, mostrava "um notável ano de prosperidade à frente, sem precedentes".$^{34}$ Tendo desaparecido a pressão monetária, os bancos estavam ansiosos por concederem empréstimos a juros mais baixos. Em 15 de janeiro, o otimismo já era muito elevado, a ponto de a Economist reclamar que os especuladores já estavam de volta. ${ }^{35}$ Por outro lado, nas semanas seguintes, as falências continuavam, especialmente entre indústrias. ${ }^{36}$ Assim como a eclosão da crise se deu no mercado financeiro, a recuperação também teve início ali, contagiando a economia real somente com alguma diferença de tempo. Novamente, Marx acompanha, no terceiro caderno, todos os mercados de matérias-primas, cada um deles, em algum momento de janeiro ou fevereiro, a manifestar a recuperação da economia. O terceiro caderno, sobre a crise comercial, portanto, acabou por detalhar todo o processo de crise e recuperação em incontáveis mercados. Cerca de dez por cento de seu conteúdo são tabelas de evolução de preços de diversos produtos primários. O que seria a derrubada se revelou apenas um ciclo acelerado de queda e retomada. Quase todo o caderno cobre apenas algumas semanas, uma análise de conjuntura profunda em seu detalhamento e em seu alcance. A maioria dos mercados analisados por Marx tem suas flutuações descritas desde dezembro até o final de janeiro. Naturalmente, o início da recuperação dos mercados de bens primários é sintoma da recuperação industrial. Os preços baixos acabaram, eventualmente, por atrair mais compradores, tanto internamente quanto no exterior. ${ }^{37} \mathrm{~A}$ certa altura, Marx toma a seguinte nota, de fonte ignorada, provavelmente do Manchester Guardian:

"Muitos pensam que, porque existe uma abundância de capital desempregado, a compra de manufaturados e outras mercadorias é certamente estimulada imediata e consideravelmente. Eles se esquecem de que é o desejo de confiança que faz com que o dinheiro aumente em inumeráveis setores

\footnotetext{
${ }^{32}$ MEGA $^{2}$ IV.14, p. 296 a 310.

${ }_{33}$ MEGA $^{2}$ IV.14, p. 311.

${ }^{34}$ MEGA $^{2}$ IV.14, p. 313.

${ }^{35}$ MEGA $^{2}$ IV.14, p. 319.

${ }^{36}$ MEGA $^{2}$ IV.14, p. 321.

${ }^{37}$ MEGA $^{2}$ IV.14, p. 412.
} 
estagnados; de que muitos estão a fazer depósitos com seus banqueiros, para estarem preparados para perdas ou demandas sobre as quais sabem serem certas ou possíveis; e de que existem muitas partes dos títulos cujos nomes não seriam aceitos em contratos, embora não tenham sido desonrados. Nesses casos, recuperação da estagnação é tornada possível inevitavelmente lenta e contida, e submetida a pausas e retrocessos. Apressar o progresso natural da recuperação é efetivamente dificultá-la, como qualquer tentativa revela de modo manifesto. Será provavelmente descoberto que o abandono do 'curto prazo' agora acontecendo seja prematuro." 38

O primeiro passo da recuperação industrial, portanto, é a própria "especulação", isto é, várias aquisições e compras são feitas graças justamente ao estado de contração de preços. $\mathrm{O}$ "capital ocioso", portanto, é a grande oportunidade de negócios que abre o caminho da recuperação, embora ainda não possa ser confundido com a própria prosperidade. $\mathrm{O}$ dinheiro que se expandiu na forma de notas bancárias sem lastros, graças à suspensão da lei bancária, fez com que os capitais ociosos mudassem de mãos, com o prejuízo de setores produtivos inteiros. Os preços baixos representaram perdas para praticamente todos os negócios, indústria e bens primários, sem benefício para consumidores no curto prazo. Esses consumidores, em última instância, eram os proletários desempregados em grande medida. Aqueles que mantiveram seus empregos tiveram os salários bastante reduzidos. ${ }^{39}$ As taxas de desemprego industrial foram enormes em alguns setores. O desemprego na indústria têxtil de Manchester, por exemplo, chegou a $25 \% .{ }^{40}$ Marx toma várias notas sobre desemprego involuntário, empobrecimento, fome e miséria; greves, rebeliões foram amplamente descritas na imprensa nas primeiras semanas de janeiro de 1858. A partir daí, o terceiro caderno de Marx assume uma forma mais irregular, com notas sobre diversos países. Assim como a crise foi paulatinamente superada, Marx deu seu trabalho por encerrado, abandonou os Grundrisse para reiniciar a redação e deixou de lado seu estudo conjuntural, registro imenso até para os padrões do mercado financeiro contemporâneo. No ano de 1858, ocupou-se enormemente com a tarefa de produzir sua crítica da economia política, sempre a prometer mais do que seria humanamente possível, conforme demonstrou Vollgraf. ${ }^{41}$ Os anos seguintes seriam de grandes realizações e, ao mesmo tempo, de constantes adiamentos. De todo modo, a análise conjuntural de 1857 deixou marcas na trajetória posterior.

A esse respeito, cabe avaliar como Marx estava preparado teoricamente para a empreitada e os passos seguintes em seu estudo sobre crises. De

\footnotetext{
${ }^{38}$ MEGA $^{2}$ IV.14, p. 419.

${ }^{39}$ MEGA $^{2}$ IV.14, p. 448.

${ }^{40}$ MEGA $^{2}$ IV.14, p. 449.

${ }^{41}$ VOLLGRAF, Carl-Erich. Marx's further work on Capital after publishing volume I: on the completion of part II of the MEGA2. LINDEN, Marcel van der. HUBMANN, Gerald. Marx's Capital: an unfinishable project? Leiden: Brill, 2018, p. 60.
} 
acordo com o Mori, Marx pretendia desenvolver, em 1857, uma teoria sobre as crises que se distanciasse de uma visão puramente financeira do fenômeno, perspectiva dominante quando do pânico de $1847^{42}$. O mercado financeiro seria apenas o ponto de partida, mas haveria uma crise de superprodução na indústria e, por outro lado, subprodução no departamento de matérias-primas. Para Mori, a pesquisa de Marx sobre a crise de 1857 teria seguido os passos do livro A History of Prices, de Thomas Tooke e William Newmarch, publicado em fevereiro de 1857. Os excertos marxianos desse livro ainda não foram publicados na coleção da MEGA $^{2}$. Mori afirma:

“(...) existem vários paralelos entre a análise de Marx da crise nos 1850s e os dois últimos volumes de Tooke e Newmarch, de fato, ambos a compartilhar a mesma visão sobre os desdobramentos econômicos que conduziram à crise de 1857, tal como formulada por Marx como sendo uma 'crise dupla'. A History of Prices descreveu - baseada nos relatórios do inspetor-chefe de fábricas e oficinas, Leonard Horner - detalhes a respeito de sobreinvestimento nos anos de boom de 1852 e 1853, que resultaram subsequentemente no aumento dos custos de matéria-prima e no decréscimo do preço dos produtos dos fabricantes de algodão." 43

O editor do volume ora discutido acaba por clarificar, portanto, que Marx, em 1857, não abandona sua concepção de "crise comercial", mas considerou-a parte essencial para a eclosão da crise em sentido estrito: a sequência de pressões monetárias a se manifestarem no mercado financeiro. Diante desse quadro, duas questões se nos apresentam: se a perspectiva marxiana se transformaria dez anos depois, ao analisar a crise de 1866, já produzidos bastantes elementos de sua própria teoria; em segundo lugar, se foi produzida uma perspectiva consistente para essa análise.

\section{A teoria entre as crises (1865) e a nova rodada de pesquisas (1868)}

Como se disse, entre 1864 e 1865, Marx redigiu o principal manuscrito para o livro terceiro, além do primeiro manuscrito para o livro segundo, sem mencionar o essencial Manuscrito de 1861-1863 e, a partir de 1864, o intenso trabalho na Internacional. Publicado o livro primeiro de $O$ Capital, tal qual fizera em 1857-58, Marx redigiu três cadernos de notas sobre a crise de 1866, além de haver tomado notas em outros cadernos sobre temas conexos ao longo daqueles anos de pesquisa intensa. Para

\footnotetext{
${ }^{42}$ MORI, Kenji. The Books of Crisis and Tooke-Newmarch excerpts: a new aspect of Marx's crisis theory in MEGA. The European Journal of the History of Economic Thought, 25 (5), 2018, p. 2. ${ }^{43}$ Ibidem, p.4.
} 
analisar as duas questões, tomemos o caminho inverso, isto é, vejamos em primeiro lugar as notas de 1868. A exposição aqui segue trabalhos de pesquisa sobre material ainda não publicado na $\mathrm{MEGA}^{2}$, cujos resultados publicamos alhures. ${ }^{44}$

Os cadernos B108, B109 e B113 totalizam pouco mais de quinhentas páginas manuscritas e serão publicados no volume IV.19 da MEGA². O caderno B108 apresenta a seguinte estrutura: 1) Banco da Inglaterra e mercado monetário; 2) investimentos no mercado de ações e quotas; 3) companhias; 4) comércio e 5) ferrovias. Esse caderno teve como base, especialmente, a publicação The Money Market Review, semanário bastante influente na década de 1860. O caderno B109, por sua vez, apresenta mais notas tomadas da Economist, e apresenta a seguinte estrutura: 1) Banco da Inglaterra e Lei Bancária de 1844; 2) teoria do pânico; 3) títulos mobiliários e pânico; 3) companhias bancárias e outras sociedades por ações; 4) ferrovias; 5) pletora de dinheiro; 5) Lei da Responsabilidade Limitada de 1862. Finalmente, o caderno B113 apresenta notas sobre o próprio ano de 1868, novamente. Publicamos em 2013 uma transcrição do índice feito pelo próprio Marx para esse caderno. ${ }^{45} \mathrm{O}$ índice que Marx fez para suas notas se divide prioritariamente em países e o Reino Unido é, naturalmente, o centro de suas preocupações. Importa ressaltar que os estudos de Marx, desta feita, assumem uma complexidade inédita. A conclusão apressada seria aquela de que, tendo já trabalhado teoricamente vários dos temas sobre mercado financeiro, ele teria condições diversas daquelas de 1857 para se debruçar sobre o objeto. No entanto, outro elemento fundamental foi a série de mutações que o próprio objeto de pesquisa sofreu. Em meio à Guerra Civil Americana, a Inglaterra, por seu turno, experimentou, a partir de 1860, modificações significativas em seu ordenamento jurídico, para acompanhar a expansão acelerada do capital internacional. Ao contrário da crise de 1857, em 1866 o epicentro do pânico foi o próprio mercado financeiro inglês. Em maio de 1866, o banco Overend, Gurney \& Co. faliu. Embora fosse um gigante no setor de desconto de letras de câmbio na primeira metade do século XIX, a partir de 1850, viu-se imerso numa série de empreendimentos duvidosos. Para evitar a falência, em 1865, o banco se tornou uma sociedade de responsabilidade limitada, inovação trazida pela lei de 1862, a saber, a responsabilidade de sócios apenas até o montante do capital subscrito. Baseado em sua reputação, o banco obteve uma grande subscrição um ano antes da falência. Em 1866, com uma série de quebras no setor de ferrovias, o banco foi ele mesmo conduzido à falência.

${ }^{44}$ PAULA, João Antonio de, et al. Notes on a Crisis: The Exzerpthefte and Marx's Method of Research and Composition. Review of Radical Political Economics, 45 (2), 2013. De Deus et al., A theory in the making: Marx's drafts of Capital and the notebooks on the crisis of 1866. Science E Society, 80 (4), 2016.

${ }^{45}$ PAULA, João Antonio de, et al. Notes on a Crisis: The Exzerpthefte and Marx's Method of Research and Composition. Review of Radical Political Economics, 45 (2), 2013, p. 172. 
Os meses seguintes apresentaram uma série de quebras e, novamente, a lei bancária de 1844 foi suspensa. A crise de 1866 foi sintoma, portanto, da separação entre propriedade do capital e sua gestão, com empresas de responsabilidade limitada a adquirir maior capacidade de alavancagem.

Esse quadro provoca uma dupla modificação na perspectiva marxiana: de um lado, o objeto sofreu algumas modificações importantes e, por outro lado, o autor está mais bem preparado do ponto de vista científico, tendo redigido a série de manuscritos já mencionada. A articulação entre as diversas instâncias só se tornou minimamente clara com a redação dos diversos esboços de $O$ Capital. A hipótese desenvolvida por Mori, portanto, merece ser considerada: quando olhamos a tematização marxiana das crises nos Grundrisse e nos cadernos de 1857/58, pode-se notar o vínculo entre a expansão do capital fixo (e os crescentes investimentos em ciência), em contradição com a produção do valor e do mais-valor na sociedade. Com efeito, em 1857, é observável a perspectiva da derrubada do capitalismo. Depois de 1863, o plano para a crítica da econômica política sofreu consideráveis transformações e, a partir dele, a abordagem das crises adquire não um caráter duplo e bastante ricardiano, mas uma perspectiva com vários elementos concêntricos, uma abordagem multidimensional. Callinicos mostra precisamente como, a partir do Manuscrito de 1861-1863, as crises adquirem, em Marx, esse caráter multidimensional, que perpassa os fenômenos da acumulação (ligados à composição orgânica do capital), da reprodução e, finalmente, da própria tendência do sistema, isto é, a abordagem marxiana está presente nos vários níveis de abstração de sua obra econômica, todas elas combinadas. Ele diz:

“Nada no que foi exposto acima sugere que O Capital contenha qualquer coisa similar a uma teoria completa da crise. A natureza inacabada do livro é particularmente evidente no livro III, acima de tudo na parte 5. No entanto, parece inegável que, em níveis sucessivos de determinação, a concepção das crises capitalistas é desdobrada através do livro. Isso envolve: (i) a possibilidade formal de crises a emergir da separação entre compra e venda, inerente à circulação de mercadorias, e da função do dinheiro como meio de pagamento; (ii) a interação entre o ciclo econômico e as flutuações do exército industrial de reserva e a taxa de salários; (iii) o papel da rotação do capital fixo na regulação da duração do ciclo econômico; (iv) a possibilidade de disrupção inerente às condições de troca entre os dois principais departamentos de produção requeridos para a reprodução; (v) a interação entre a tendência de queda da taxa de lucro e seus fatores contrários; e (vi) a função do ciclo de bolha e pânico nos mercados financeiros, nos dois casos, durante booms, a acelerar o processo de acumulação e, durante crises, a efetuar a destruição de capital requerida para restaurar a taxa de lucro a um nível que permita posterior expansão." ${ }^{\prime 46}$

\footnotetext{
${ }^{46}$ CALLINICOS, Alex. Deciphering Marx. Londres: Bookmarks, 2014, p. 282.
} 
Em 1868, embora Marx estivesse longe de produzir os manuscritos mais densos para o livro segundo, como se disse anteriormente, já tinha clara então a articulação entre os diversos níveis de análise da economia capitalista e, por conseguinte, das diversas instâncias da crise econômica. O papel do livro terceiro, in casu, do Manuscrito de 1864-1865, é essencial nessa trajetória. De fato, o título planejado para ele seria das "formas do processo completo", isto é, a manifestação da crise econômica se daria exatamente a partir da atuação da tendência de queda da lucratividade e de sua contraditória interação com fatores contrários e, sobretudo, a partir da forma mais aparente do fenômeno, qual seja, o mercado financeiro (do ponto de vista teórico, portanto, a abordagem da crise pressupõe a tematização prévia de preço e lucro médio). Os efeitos retroativos da crise, no entanto, manifestar-se-iam nitidamente até o desemprego e a destruição física de capitais e mercadorias. Cabe apontar, diante disso, como Marx pensou então a crise e seus desdobramentos no nível mais complexo da sociedade capitalista, meditação que estava subjacente a suas leituras da crise de 1866 e, em contrapartida, ausente dez anos antes.

O quinto capítulo do Manuscrito de 1864-1865 (que se tornaria a quinta seção do livro terceiro) lida com o "capital portador de juros", o supremo fetiche capitalista, fazer dinheiro a partir de dinheiro: D-D'. Depois de toda a trajetória iniciada com a mercadoria, chega-se ao capital creditício em suas diversas formas, conclusão do processo de reificação social, que atinge o próprio capital, ele mesmo, no mercado financeiro, transformado em mercadoria sujeita à demanda e à oferta, isto é, com um preço, o juro. Toda essa parte do manuscrito pretende abordar dois pontos nem sempre distintos na economia política e mesmo na vida política do tempo: as relações entre dinheiro e crédito e, em segundo lugar, entre crédito e acumulação capitalista. Parte do quinto capítulo recebeu justamente o subtítulo de "A confusão", notadamente quando Marx analisa as discussões no parlamento inglês sobre a crise de $1857 .{ }^{47}$

A abordagem marxiana da crise e da dinâmica econômica, nessa parte do manuscrito, merece ser lida em conjunto com a seção da lei de tendência de queda da taxa de lucro, algo nem sempre considerado. Autores como Heinrich têm criticado o lugar da lei na arquitetura de O Capital, a indicar que a tematização sobre crises só seria exequível justamente na quinta seção do livro terceiro (quinto capítulo do manuscrito). ${ }^{48}$ Heinrich busca demonstrar como a dedução de Marx para a lei é insuficiente, as variáveis envolvidas na taxa de lucro - mais-valor, capital total ou, na forma transformada, taxa de mais-valor e composição orgânica - não produzem, em realidade,

${ }^{47}$ MARX, Karl. ENGELS, Friedrich. Gesamtausgabe, II.4.2. Berlim: Akademie, 2012, p. 597 e ss. ${ }^{48}$ HEINRICH, Michael. Die Wissenschaft vom Wert. Münster: Westfälisches Dumpfboot, 1999 (4 $4^{\mathrm{a}}$ edição, 2006), p. 330 e ss. 
uma tendência, mas antes efeitos ambíguos e indeterminados, qualquer que seja o prazo considerado. Diz Heinrich:

“Não importa com qual variante argumentativa nos aproximemos de uma determinação do movimento da taxa de lucro, estamos sempre diante do mesmo problema. Temos duas grandezas variáveis (taxa de mais-valor e composição orgânica, massa de mais-valor e tamanho do capital, encarecimento e barateamento dos elementos do capital constante), das quais uma é conhecida como direção do movimento de longo-prazo. ${ }^{49}$ Entretanto, para a direção do movimento da taxa de lucro, emerge a proporção do movimento dessas duas quantidades, que se altera mais rápido em relação à primeira e domina com isso os eventos. No entanto, não se pode fazer em absoluto uma tal comparação, que se refere apenas à direção do movimento das grandezas a comparar, com informações qualitativas. Portanto, não é absolutamente possível a demonstração geral buscada por Marx de que a taxa de lucro tenha uma tendência inevitável a cair, em razão do desenvolvimento capitalista das forças produtivas." 50

A proposição de Heinrich, nos anos seguintes, tornou-se um dos objetos centrais das polêmicas em torno da obra marxiana. $\mathrm{O}$ método de exposição marxiano, bem como os métodos matemáticos disponíveis eram insuficientes então e a própria natureza da lei permaneceu, com isso, obscura. Em 2012, v.g., Kliman tentou apresentar uma nova metodologia para responder às indagações aqui formuladas, muitas outras foram realizadas. ${ }^{51} \mathrm{O}$ que nos interessa aqui, todavia, é a articulação que Marx efetua entre os efeitos contraditórios da lei com a crise econômica, isto é, a perspectiva de que as crises financeiras em geral estão vinculadas ao próprio funcionamento do capitalismo, um sistema dinâmico e aberto que supera as contradições que ele mesmo se põe. A análise do texto marxiano se torna difícil neste quesito em razão da edição feita por Engels para a seção sobre a lei tendencial.

Em sua importante apresentação à tradução inglesa do Manuscrito de 18641865, Fred Moseley constatou dois pontos importantes. Em primeiro lugar, a edição engelsiana fez o texto de Marx parecer mais organizado do que de fato era. ${ }^{52}$ Em segundo lugar, em algumas passagens da edição, Engels modificou palavras para fomentar as teorias da derrubada na II Internacional. ${ }^{53} \mathrm{O}$ mais importante para o ponto aqui, entretanto, é a constatação

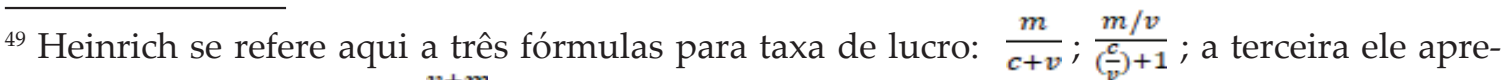
senta como a proporção $\frac{v+m}{c}$, trabalho vivo e trabalho objetivado, que, ao cair tendencialmente faria com que a taxa de lucro também caísse.

${ }^{50}$ Ibidem, p. 337.

${ }^{51}$ Cf. a respeito RIBEIRO, Leonardo Costa, et al. Profits and fractal properties: notes on Marx, countertendencies and simulation models. Review of Political Economy, 29 (2), 2017. ${ }^{52}$ MOSELEY, Fred. Introduction. MARX, Karl. Economic Manuscript of 1864-1865. Leiden: Brill, 2015. p. 19.

${ }^{53}$ Ibidem, p. 20.
} 
de que aquilo que se tornaria o capítulo 15 do livro terceiro apresentaria, segundo Moseley, uma perspectiva consistente sobre a tendência de queda da taxa de lucro e seu vínculo com as crises econômicas. Ele diz:

\begin{abstract}
“A seção 1 [do texto convertido por Engels no capítulo 15 - LGD] ressalta três pontos principais: as proporções relativas de lucro industrial, juro e renda podem ter sido diferentes da taxa geral de lucro; um decréscimo na taxa de lucro pode ser acompanhado por um acréscimo na taxa de lucro; e o declínio na taxa de lucro não é devido à exploração reduzida, mas ao declínio no número de trabalhadores empregados. O principal ponto da seção 2 é que o desenvolvimento da produtividade do trabalho no capitalismo tem dois efeitos principais - um aumento do sobretrabalho por trabalhador e um decréscimo no número de trabalhadores empregados - e esses dois efeitos, ao seu turno, têm efeitos opostos na taxa de lucro. A seção 3 apresenta um esboço de uma teoria pioneira do ciclo capitalista de expansão-contração, o que decorre diretamente da teoria de Marx da queda da taxa de lucro. Se as crises capitalistas são causadas pela taxa de lucro cadente, então a recuperação das crises requer, antes de tudo, uma restauração da taxa de lucro aos níveis mais elevados de antes. Além disso, se a causa subjacente de uma taxa de lucro em queda é um aumento na composição orgânica do capital (a razão entre capital constante e capital variável), então, a restauração da taxa de lucro requer uma redução no valor da composição orgânica do capital, o que é tipicamente realizado durante depressões capitalistas pela desvalorização do capital, que resulta da quebra generalizada de empresas capitalistas. Portanto, a teoria de Marx não apenas prevê crises capitalistas recorrentes, mas também prevê que a precondição para a recuperação das crises é a desvalorização do capital e falências generalizadas. O esboço de uma teoria dos ciclos capitalistas nessa seção está certamente longe de uma teoria completa, mas está muito à frente de outras teorias em qualquer época (que mal reconhecem a tendência do capitalismo às crises), e eu acho que permanece hoje uma estrutura útil única para analisar os ciclos de expansão-contração do capitalismo." ${ }^{54}$
\end{abstract}

Não poderíamos concordar mais. A interação entre a tendência e as suas circunstâncias contra-arrestantes gera uma superabundância de mercadorias e capital ("pletora de capitais") e, por isso, crise econômica. Já em 1865, a obra de Marx consegue captar a capacidade do capitalismo de superar suas barreiras, algo reproduzido em sua abordagem, no livro primeiro, sobre a acumulação capitalista. Moseley ${ }^{55}$ ainda chama atenção para uma frase de Marx no manuscrito, nessa altura: "uma investigação detalhada sobre isso pertence à investigação sobre o movimento aparente do capital, onde capital portador de juros etc. crédito etc. são examinados com mais detalhe" ${ }^{\prime 56}$ Os editores da MEGA consideram que essa advertência decorreria do fato de que, com a mudança de planos de 1863-1864, Marx teria

${ }^{54}$ Ibidem, p.21

${ }^{55}$ Ibidem, p.22.

${ }^{56}$ MEGA $^{2}$ II.4.2, p. 325. 
abandonado o estudo do "movimento aparente", ou seja, teria adiado uma pesquisa empírica para outra ocasião, enquanto os três livros teóricos de O Capital estariam circunscritos, no caso do crédito e do juro, àquilo em que se relacionariam com o capital industrial propriamente dito. ${ }^{57} \mathrm{No}$ entanto, a redação do Manuscrito de 1864-1865, em seu quinto capítulo, assumiu proporções que fugiram desse desígnio e que acabam por reforçar a tese de Moseley, de que existe um elo, mesmo que tênue, entre a lei de tendência de queda da taxa de lucro e seu movimento aparente, a saber, o ciclo de contração-expansão, que só se poderia manifestar no mercado financeiro, forma aparente do capital que já apresenta taxa de lucro médio, com tendência de queda e com tendência a superar, via crise, suas próprias contradições. Vejamos, então, como essa perspectiva é desenvolvida por Marx em seguida, no quinto capítulo de seu manuscrito. ${ }^{58}$

\section{O ciclo de expansão-contração}

A perspectiva enunciada acima parte da constatação de que as diversas formas fenomênicas do capital (mercantil, comercial, monetário) não previnem a elaboração de uma teoria do ciclo econômico. Os passos analíticos necessários são a construção teórica de uma taxa de lucro médio e a determinação de sua tendência de queda. A manifestação de um e outro fenômeno combinados se dá no que hoje em dia se chama de mercado financeiro, algo que está alinhado com a forma de manifestação empírica das crises de ontem e de hoje. Essa a tônica da abordagem marxiana no Manuscrito de 1864-1865, fruto da interpretação da crise de 1857 e aparato para a análise da crise que ocorreria nos anos seguintes.

O capital portador de juros, objeto do quinto capítulo do Manuscrito de 1865-1865 é aquele que atua como se mercadoria fosse, ou seja, apresenta oferta e demanda e um preço, o próprio juro. O mercado de crédito, para Marx, expande-se endogenamente, é elástico em relação aos tempos de prosperidade material, de expansão da produção. Em tempos de aceleração econômica, o dinheiro tem aumentada sua velocidade de circulação, de modo a remunerar uma maior rentabilidade (mais-valor) dos diversos capitais, em outras palavras, do capital global da sociedade, "período de most elastic and easy credit." 59 Fácil notar aqui o polo oposto em que Marx se coloca em relação a teorias exógenas do crédito e da moeda. O processo de reprodução acelerado implica aceleração da circulação de dinheiro para liquidações de operações, pagamentos entre capitalistas, bem como

\footnotetext{
${ }^{57}$ MEGA $^{2}$ II.4.2, p. 1255.

${ }^{58}$ A exposição a partir daqui segue meu trabalho de 2015.

${ }^{59}$ MEGA $^{2}$ II. 4.2, p. 509.
} 
para remuneração do capital variável em expansão, isto é, a demanda por capital aumenta e o dinheiro tem de ser capaz de satisfazer tanto esses pagamentos quanto a própria circulação de mercadorias (meio de troca), com isso, a oferta de crédito se expande e os juros caem.

O período de contração econômica, por outro lado, implica diminuição da quantidade de dinheiro como meio de circulação e pagamento, em razão da queda de preços, salários e do número de transações. Nesse momento, o crédito diminui e os juros apresentam um comportamento peculiar. Marx diz:

“Se considerarmos os ciclos em que a indústria moderna se move - estado
de tranquilidade, crescente animação, prosperidade, superprodução, crise,
estagnação, tranquilidade etc. - (...) descobrimos que, geralmente, baixas
taxas de juros correspondem a períodos de prosperidade ou de lucros
extraordinários, aumento no juro é a fronteira entre prosperidade e seu
reverso, mas o máximo de juro até a extrema usura corresponde à crise."60

A crise exige uma "acomodação monetária": a oferta de capital como tal diminui, mas não a demanda de crédito. Com isso, a demanda por capitais em suas formas particulares, quais sejam, mercadoria, dinheiro e capital produtivo diminuem. Porém, a demanda por capital financeiro, bancário, ${ }^{61}$ aumenta na forma de crédito, fazendo com que os juros subam. Isso ocorre, segundo Marx, para que os capitalistas em dificuldade tenham acesso a parte do valor poupado por toda a sociedade, pressionando assim o capital bancário, seja na forma de ações, títulos do governo (títulos de propriedade sobre o capital), para que se converta em capital-dinheiro. Há, com isso, uma pressão não sobre o capital, mas especificamente sobre o capital bancário. Esse processo, em última análise, resulta na transformação do capital-dinheiro em dinheiro mundial (crise cambial e do balanço de pagamentos). Portanto, aqui, o capital faz o caminho de volta: deixa de ser capital para ser dinheiro e, como se verá, mercadoria. Torna-se dinheiro de novo para satisfazer a demanda por meios de circulação e pagamento das próprias pessoas do capital. A crise promove, com isso, uma redistribuição do estoque de valor disponível na sociedade, o que só é possível na forma de dinheiro.

Segundo Marx, o principal sintoma desse mecanismo é a "pletora de capitais" que, após períodos de expansão, não encolhe durante a crise, mas simplesmente muda de mãos, ou de forma. A contração na produção implica menos capital produtivo, menos oportunidades de investimento. Com isso, o estoque de capital bancário, financeiro, tem de se converter em dinheiro novamente. Seu estoque aumenta na inversa proporção do capital produtivo. Aqui se encontra a manifestação da crise, tal qual abordada na

${ }^{60}$ MEGA $^{2}$ II.4.2, p. 433.

${ }^{61}$ Emprego "capital financeiro" aqui em sua acepção contemporânea, não como aparece em O Capital. 
seção dedicada à lei de tendência de queda da taxa de lucro, o excedente de capital que tem necessariamente de moldar a vida produtiva para voltar a lucrar. Por outro lado, marxianamente, a grande novidade das crises do século passado e deste seria precisamente a capacidade de o Estado realizar de maneira controlada essa expansão monetária.

A partir de 1865, Marx não trabalha com duas crises, mas várias crises concêntricas. Portanto, parece ser razoável apontar uma mudança em relação a 1857. A crise tem início na produção, com uma oferta abundante e queda de preços, excesso de valores de uso, inovação, diminuição do valor das coisas. O mecanismo de contágio, por outro lado, ocorre no balanço de pagamentos (dinheiro mundial), com queda da oferta de capital (crédito), perda de dinheiro mundial e alta de juros, mudança do balanço dos bancos. O capital financeiro e sua transformação em dinheiro para circulação e pagamento, finalmente, medirão a transferência de valores entre capitalistas, entre os diversos ramos de produção e, finalmente, a proporção entre capital constante e variável. Marx diz: “(...) depois de cada período de crise, o nível mais elevado de capital financeiro do ciclo industrial precedente se torna a base do nível mais baixo do período seguinte." ${ }^{62} \mathrm{E}$, mais adiante, constata:

"Por exemplo, na fase adversa do ciclo industrial, a taxa de juros sobe a um alto nível, de modo a devorar os lucros por algum tempo. Ao mesmo tempo, os preços de títulos públicos e outros caem. Esse é o momento em que a massa de capitalistas investe nesses títulos depreciados para que, nas próximas fases, eles subam além de seu nível normal. Então, eles serão vendidos a qualquer preço e, assim, uma parte do capital financeiro do publicum será apropriada. A parte que é mantida porque comprada abaixo do preço terá seu retorno aumentado. Todos os lucros obtidos, porém, e que eles reconverterão em capital são, primeiro, convertidos em capital para empréstimo, financeiro. A acumulação desse último, diferente da acumulação real, embora seu fruto, é que ocorre, portanto, mesmo quando consideramos apenas os capitalistas financeiros (banqueiros etc.) por si mesmos, como acumulação dessa classe particular de capitalistas. E eles têm de prosperar a cada expansão de crédito, já que ela acompanha a expansão real do processo de produção." 63

O capital financeiro é, ele mesmo, uma parte de todo o estoque de capital, ainda que na forma de títulos sobre o capital produtivo. A crise promove, assim, uma redistribuição entre esses dois gêneros de capitalistas, eventualmente em nível internacional. O papel do crédito, nesse momento, é precisamente de unificar os diversos circuitos do sistema, fazendo com que a crise atinja, ao mesmo tempo, todos os indivíduos envolvidos na vida econômica. Eventualmente, parcelas inteiras da vida produtiva de um país

\footnotetext{
${ }^{62}$ MEGA $^{2}$ II.4.2, p. 553.

${ }^{63}$ MEGA $^{2}$ II.4.2, p. 557.
} 
são sacrificadas nesse processo. Uma contração no crédito implica que, para se garantir a convertibilidade do dinheiro (existência autônoma do valor) em mercadorias, muitas delas serão sacrificadas para que se garanta essa autonomia, isto é, o funcionamento da acumulação de trabalho social. E Marx arremata, de modo um tanto surpreendente: "Isso é inevitável na produção burguesa e constitui uma de suas belezas." ${ }^{64}$

O processo de produção e reprodução do capital implica a expansão dos valores de uso, do valor, do estoque de mercadorias e de dinheiro na vida social. Em um dado momento, no entanto, temos a produção de capital supérfluo, ou seja, o capital é sempre capaz de lucrar com menos estoque, o que equivale a dizer que, enquanto esse estoque não diminui, cai a taxa de lucro. A manifestação desse fenômeno é a crise econômica, que eclode ali onde o capital é comprado e vendido. O caminho do ajuste é o percurso contrário, que resultará na destruição de capital-mercadoria, no desemprego, em outras palavras, na redução do estoque material, enquanto o estoque de riqueza em mãos de capitalistas apenas sofre transformações. $\mathrm{O}$ ajuste, entretanto, continua a ocorrer no nível da vida social e material dos povos. Essa a perspectiva assumida por Marx antes da eclosão da crise de 1866 e, em grande medida, presente nas várias e sucessivas elaborações de seus esboços para sua obra econômica. É bastante conhecida a importância que o próprio Marx atribuía a esse itinerário, mas também é necessário reconhecer os seus limites. A derrubada do capitalismo não ocorreria por obra e graça da decadência econômica, mas pela ação prática e emancipatória. Esses temas, por sua vez, percorrerão não apenas os últimos anos de Marx, mas todos os anos de sua recepção, no século passado e neste.

\section{Conclusão}

Embora tenham testemunhado o desaparecimento do marxismo como possibilidade prática, os últimos cinquenta anos, por isso mesmo, permitiram abordagens mais livres da obra marxiana. Por conta de seu caráter e de sua ineliminável vocação prática, essa se viu, no século passado, imersa em debates fúteis, enquanto ficou sempre afastada de atuação efetiva em debates essenciais. Foi muito tardiamente, por exemplo, que a filosofia marxiana foi reposta em seu diálogo frutífero com a tradição, pela pena do último Lukács. Um dos elementos centrais da redescoberta de Marx nesse século passa, necessariamente, pela constatação de seu caráter ontológico. Nas palavras de José Chasin:

"Sem o espírito ou dimensão ontológica, ou seja, sem o estatuto de uma filosofia primeira, é impossível sequer perceber quais são, num dado momen-

${ }^{64}$ MEGA $^{2}$ II.4.2, p. 594. 
to, os problemas científicos verdadeiros - o que deve ser estuado, qual a hierarquia dos mesmos e sua posições do quadro hierárquico das urgências sociais - nem se posicionar em face das vertentes, sem cair na falácia da equivalência e/ou complementaridade das mesmas, ou ainda sucumbir, de forma ainda mais deletéria, à invocação do pluralismo, que de invocação antidogmática passa à simples condição de camuflagem da ignorância e subterfúgio do oportunismo em teoria." ${ }^{65}$

A posição filosófica correta não garante, mas é requisito para a prática emancipatória, é parte integrante dela. Sem isso, a ênfase recai, necessariamente, na política e no politicismo, no voluntarismo que, inevitavelmente, resulta em reforço do próprio sistema que se pretende superar, isto é, mero predicado da decadência material e cultural do tempo.

Outro debate em que o marxismo entrou de maneira atrasada e precária foi a abordagem dinâmica das crises econômicas. Quando o marxismo se colocou o problema, o campo da retórica econômica já estava totalmente tomado. Esse artigo se inscreveu num esforço de

vários atores para que a trajetória possa ser corrigida, vencidos que foram vários debates secundários, dentro dos termos da ciência econômica capitalista, seja ela ortodoxa ou não.

Um dos elementos que emergem das pesquisas de Marx, bem como de sua atuação política, é justamente a constatação que o autor efetuou, a partir da década de 1870, do caráter violento da superação das crises. A acumulação acelerada e o desenvolvimento sem precedentes das forças produtivas do trabalho social implicaram, na segunda metade do século XIX, uma expansão exponencial do tamanho do Estado e de seu papel na vida social. A repressão sanguinária a vários movimentos revolucionários, notadamente a Comuna de Paris, as guerras internacionais com baixas superlativas fizeram Marx constatar que a violência de Estado é parte da solução das crises que ele estudara. Esse elemento só se tornaria explícito por completo, dentro do marxismo, a partir do bolchevismo. A expansão do capitalismo não teria apenas países e empresários vencedores, mas produziria desigualdades em escala global, fato enunciado já na primeira edição de $O$ Capital. Se a crise não é prenúncio inevitável da derrubada do capitalismo, essa derrubada não se daria sem o emprego de uma força contrária de dimensões certamente maiores, a ação dos trabalhadores em escala planetária, nada menos do que isso. No século que corre, essa ação não parece possível, a subsunção do trabalho ao capital ultrapassou sua última fronteira, qual seja, a anulação total de qualquer perspectiva emancipatória, a imersão completa na vida mental e na prática do próprio capitalismo, o que implica o congelamento da luta de classes. Esses os

${ }^{65}$ CHASIN, José. Ad Hominem: rota e prospectiva de um projeto marxista. Ensaios Ad Hominem, I (3), 2000, p. 14, grifo do autor. 
impasses que, há cento e cinquenta anos atrás, pareciam absolutamente impensáveis. Num e noutro momento, é mais do que necessária a correta reflexão sobre os limites e possibilidades desse modo de vida que, sistematicamente, conseguiu prolongar, por vários e renovados meios, sua utilidade histórica.

\section{Referências}

CALLINICOS, Alex. Deciphering Marx. Londres: Bookmarks, 2014.

CALOMIRIS, Charles W.; SCHWEIKART, Larry. The panic of 1857: origins, transmission, and containment. The Journal of Economic History, 51 (4), 1991.

CHASIN, José. Ad Hominem: rota e prospectiva de um projeto marxista. Ensaios Ad Hominem, I (3), 2000.

DE DEUS, Leonardo Gomes. Tudo será como antes: o marxismo e a dinâmica econômica. OLIVEIRA, Edneia Alves de. LAMAS, Fernando Gaudereto. Ciências Humanas e Pensamento Crítico. Rio de Janeiro: Lumen Juris, 2015.

DE DEUS, Leonardo Gomes, et al. A theory in the making: Marx's drafts of Capital and the notebooks on the crisis of 1866. Science \& Society, 80 (4), 2016.

EVANS, David Morier. The history of the Commercial Crisis, 1857-1858, and the stock exchange panic of 1859. Londres: Groombridge \& Sons, 1859.

HEINRICH, Michael. Die Wissenschaft vom Wert. Münster: Westfälisches Dumpfboot, 1999 (4 edição, 2006).

HOBSBAWM, Eric. A fortuna das edições de Marx e Engels. HOBSBAWM, Eric. História do Marxismo, v. 1: O marxismo no tempo de Marx. São Paulo: Paz e Terra, 1979.

KLIMAN, Andrew. The failure of capitalist production. Londres: Pluto Press, 2012.

MOSELEY, Fred. Introduction. MARX, Karl. Economic Manuscript of 1864-1865. Leiden: Brill, 2015.

PAULA, João Antonio de, et al. Notes on a Crisis: The Exzerpthefte and Marx's Method of Research and Composition. Review of Radical Political Economics, 45 (2), 2013.

MARX, Karl. Briefe über das Kapital. Berlim: Dietz, 2010.

MARX, Karl. ENGELS, Friedrich. Gesamtausgabe, II.4.1. Berlim: Dietz, 1988.

MARX, Karl. ENGELS, Friedrich. Gesamtausgabe, II.4.2. Berlim: Akademie, 2012.

MARX, Karl. ENGELS, Friedrich. Gesamtausgabe, II.4.3. Berlim: Akademie, 2012.

MARX, Karl. ENGELS, Friedrich. Gesamtausgabe, II.14. Berlim: Akademie, 2003.

MARX, Karl. ENGELS, Friedrich. Gesamtausgabe, IV.14. Berlim: De Gruyter Akademie, 2017.

MARX, Karl. ENGELS, Friedrich. Werke, v. 32. Berlim: Dietz, 1974. 
MORI, Kenji. The Books of Crisis and Tooke-Newmarch excerpts: a new aspect of Marx's crisis theory in MEGA. The European Journal of the History of Economic Thought, 25 (5), 2018.

RIBEIRO, Leonardo Costa, et al. Profits and fractal properties: notes on Marx, countertendencies and simulation models. Review of Political Economy, 29 (2), 2017.

VOLLGRAF, Carl-Erich. Marx's further work on Capital after publishing volume I: on the completion of part II of the MEGA2 . LINDEN, Marcel van der. HUBMANN, Gerald. Marx's Capital: an unfinishable project? Leiden: Brill, 2018.

Endereço do Autor:

Universidade Federal de Minas Gerais

Faculdade de Ciências Econômicas

Centro de Desenvolvimento e Planejamento Regional

Av. Antonio Carlos, 6627 - Pampulha

31270-901 Belo Horizonte - MG

lgdeus@uol.com.br 